\title{
La cooperación entre cooperativas: ¿principio o necesidad?
}

Cooperation among cooperatives: principle or need?

\author{
Dante Cracogna' \\ Universidad de Buenos Aires (Argentina)
}

Sumario: I. Marco conceptual II. Raíces históricas III. La doctrina IV. La economía V. Condicionamiento legal VI. Conclusión.

Summary: I. Conceptual framework II. Historical roots III. The doctrine IV. The economy V. Legal conditioning VI. Conclusión.

Resumen: El artículo comienza planteando el significado de "principio», tanto desde el punto de vista gramatical como filosófico, y lo relaciona con el sentido de necesidad analizado en sus sentidos lógico y moral para luego aplicar estos conceptos al ámbito de la doctrina cooperativa. Contra ese telón de fondo, a continuación formula un desarrollo específicamente concerniente al principio de cooperación entre cooperativas con diferentes enfoques. Comienza con un repaso histórico de las raíces de la integración cooperativa en las primeras manifestaciones del cooperativismo y continúa con la consideración de la cooperación entre cooperativas en el terreno de la doctrina cooperativa acerca de la cual realiza una sintética exposición de la evolución operada hasta la Declaración sobre la Identidad Cooperativa formulada por la Alianza Cooperativa Internacional en 1995. Los capítulos siguientes están dedicados a analizar la aplicación del principio en el marco de la economía contemporánea y los condicionamientos que la legislación impone a su vigencia dentro del marco de una economía altamente competitiva. Concluye el trabajo con una referencia al sentido de la integración como unión de las partes de un todo según las concepciones de distintos autores que llevan a considerar la síntesis de principio y necesidad.

Palabras clave: principios cooperativos; cooperación entre cooperativas; Alianza Cooperativa Internacional.

Abstract: The article starts dealing with the meaning of the word «principle» from the point of view both of philosophy and grammar. Against that background it goes on considering specifically the principle of cooperation among cooperatives exploring briefly about its historical origins and the incor-

1 Email: dcracogna@estudiocracogna.com.ar. 
poration into the cooperative doctrine in different stages up to the Statement on the Cooperative Identity approved by the ICA Centennial Congress in 1995. The following paragraphs are devoted to the economic meaning of the principle and the influence of the law on its application in a world of a highly competitive economy. Finally, the author concludes with a reference to the meaning of this principle as "cooperative integration» in the sense of uniting the different parts of a whole and the ideas of different authors that lead to the synthesis of principle and need.

Keywords: cooperative principles; cooperation among cooperatives; International Cooperative Alliance. 


\section{Marco conceptual}

¿Qué es un principio? La investigación acerca de su significado conduce a encontrar múltiples y variadas acepciones. En efecto, el diccionario de la Real Academia ofrece una decena, pero entre ellas la que conviene a los fines de esta disertación es la que define al principio como «idea fundamental que rige el pensamiento o la conducta». Por otro lado, ya Aristóteles cuando estudió el significado de esta palabra refirió seis y solo uno de ellos se vincula con movimientos o cambios en el gobierno o magistraturas de la ciudad. ${ }^{2}$ Empero, a todo evento, su sentido se relaciona con el punto de partida y el fundamento de un proceso cualquiera.

Ahora bien, ¿tienen los principios un contenido de necesidad? Dicho de otra manera, ¿entrañan acciones o conductas que han de cumplirse inevitablemente, aun con independencia de estar incluidas en ellos? La necesidad es la condición sin la cual algo no puede llegar a ser; por lo tanto, su fuerza potencial es ineluctable para la realización de su fin, no puede controvertirse. En el terreno moral o de las conductas, se suele identificar la necesidad con lo obligatorio o lo que se debe realizar, lo cual implica una forma de lo necesario diferente de su sentido lógico o causal. ${ }^{3}$

Llevados estos conceptos al ámbito de la doctrina cooperativa encontramos aspectos que introducen algunas significativas matizaciones que resulta de interés analizar. En primer lugar, se suele afirmar que los principios cooperativos constituyen el camino que debe transitarse para el logro de los ideales que el cooperativismo persigue. ${ }^{4}$ Queda, pues, claro que principios e ideales no se confunden: los últimos constituyen un estado de perfección que es, por definición, inalcanzable, en tanto que los primeros consisten en el sendero que marca el rumbo a seguir cuando se aspira a lograr ciertos ideales, aun sabiendo que nunca podrán ser plenamente conseguidos. Ahí radica el sentido de los principios

2 Aristóteles, Metafísica, V. 1, 1012b.

3 Abbagnano, Nicola, Diccionario de Filosofía, trad. A. Galletti, Fondo de Cultura Económica, México, 1993, p. 846.

4 Arnold Bonner, destacado doctrinario inglés, enseñaba en el Colegio Cooperativo de Gran Bretaña una materia titulada, precisamente, «ldeals and Principles of Cooperation» en la que plasmaba esa concepción, posteriormente recogida en el Informe de la Comisión —que Bonner integró- encargada del estudio de la reformulación de los principios cooperativos designada por el Congreso de la $\mathrm{ACl}$ realizado en Bournemouth en 1963 y que fuera adoptada por el siguiente Congreso (Viena, 1966). Cfr. International Cooperative Alliance, Twenty-Third Congress Agenda and Reports, London, 1966, p. 17. 
cooperativos: son una guía para la acción cuya observancia asegura la propensión hacia los ideales cooperativos. ${ }^{5} \mathrm{Y}$ aun dentro del sendero de los principios se puede marchar por el centro o por alguno de sus costados, sin salir de él; precisamente en esa relativa amplitud se ubican las diferentes políticas o prácticas que las cooperativas pueden adoptar.

Como se ve, los principios no tienen una rigidez extrema y, por otra parte, pueden las conductas cooperativas apartarse de de ellos de manera más o menos abierta o continuada. De allí que la necesidad no adquiera el carácter de ineluctabilidad lógica o causal, pero la conclusión es que para estar en la senda correcta deben observarse los principios.

\section{Raíces históricas}

La Cooperativa de Rochdale, reconocida como la primera manifestación del cooperativismo mundial y origen de los principios cooperativos universales, no contenía en su estatuto una mención expresa de la cooperación entre cooperativas. ${ }^{6}$ Ello parecería lógico en una organización cuya originalidad resulta indiscutible aun cuando hacia la época de su fundación se habían producido varias experiencias más o menos similares en la misma región, pero no existía conciencia de identificación entre ellas o de pertenencia a un movimiento común.

Sin embargo, poco tiempo después comenzaron a tejerse lazos de vinculación con otras entidades para llevar a cabo emprendimientos conjuntos, el primero de los cuales fue la Sociedad del Molino Harinero, una cooperativa destinada a abastecer de ese producto de primera necesidad en la que había personas físicas asociadas e incluso participaron como inversoras algunas organizaciones de características afines como las mutuales del lugar. ${ }^{7}$

5 En la Declaración sobre la Identidad Cooperativa se efectúa una interpretación similar de los principios como guía o pauta para la realización de los valores que la misma Declaración enuncia, diciendo: "Los principios cooperativos son pautas mediante las cuales las cooperativas ponen sus valores en práctica». Es decir, reemplaza «ideales» por «valores».

6 No obstante, se ha señalado que el estatuto original de Rochdale hacía una mención de la intercooperación en cuanto preveía que la Cooperativa concurriría en ayuda de otras entidades que se propusieran establecer colonias autosuficientes, tal como Robert Owen postulada. Cfr. Lambert, Paul, La Doctrine Coopérative, Les Propagateurs de la Coopération —La Fédération Nationale des Coopératives de Consommation, Bruxelles- Paris, 1959, Annexe II, p. 301.

7 Holyoake, Georges Jacob, Historia de los Pioneros de Rochdale, trad. B. Delom, Intercoop, Buenos Aires, 1975, p. 47. 
No mucho más tarde plasmó la creación de una organización que perfiló de manera más precisa la colaboración entre las cooperativas de consumo de la región sentando las bases de una permanente cooperación estructurada de manera orgánica: la cooperativa mayorista del Norte de Inglaterra devenida pocos años más tarde en la CWS. ${ }^{8}$

El siguiente paso fue la formación de una entidad de colaboración destinada a actividades no económicas sino de coordinación, educación y difusión de las cooperativas, años después denominada Unión Cooperativa. ${ }^{9}$ Quedaban de esa suerte definidas las dos líneas que la cooperación entre cooperativas habría de seguir en el futuro: la integración económica y la integración representativa, culminando esta última con la fundación de la Alianza Cooperativa Internacional en 1895, máxima expresión de la integración representativa en el nivel internacional. ${ }^{10}$

Así surge de manera espontánea la cooperación entre cooperativas como una necesidad natural del desarrollo y el crecimiento cooperativo, sin que existiera una premisa o principio que la postulara. ${ }^{11}$

\section{La doctrina}

Durante mucho tiempo el plexo de los principios cooperativos no dio cabida a la cooperación entre cooperativas. Obviamente, ello no significa que estuviera conceptual o prácticamente excluida. Por el contrario, desde primer punto de vista ella representa la natural prolonga-

8 Thompson, David J., Weavers of Dreams. Founders of the Modern Co-operative Movement, Center for Cooperatives, University of California, Davis, 1994, p. 75 \& ss.

9 Cole, G.D.H., A Century of Co-operation, George Allen \& Unwin, Ltd., 1944, p. 198 y ss. hace un vívido relato de las alternativas del nacimiento y desarrollo de la Cooperative Union. Por su parte, Bailey, Jack, The British Co-operative Movement, Hutchinson University Library, London, 1960, p. 97 ff. sostiene que la Unión Cooperativa fue adecuando sus actividades en función de las cambiantes necesidades del movimiento cooperativo británico a partir de su constitución como Consejo Central (Central Board) de las cooperativas en 1870.

10 El surgimiento de la $\mathrm{ACl}$ y la historia de sus primeros 75 años de existencia están fielmente reflejados por William Pascoe Watkins, quien fuera su director durante años, en The International Cooperative Alliance 1895-1970, International Cooperative Alliance, London, 1970, en cuya portada se lee este revelador párrafo del Informe fundacional del Congreso de la ACI celebrado en Londres en 1895: "Every body of Co-operators is, by the very principle it professes, driven to desire union with every other body of Co-operators.»

11 Antes de estudiar los antecedentes de la formulación del principio, Alejandro Martínez Charterina, con acierto, se refiere a lo que denomina las grandes razones para la integración (Análisis de la integración cooperativa, Universidad de Deusto, Bilbao, 1990, p. 11 y ss). 
ción de la ayuda mutua del ámbito de las relaciones entre las personas al de las relaciones entre las entidades cooperativas; se trata, simplemente, de mantener y proyectar la actitud que define a la cooperación en sentido general. ${ }^{12}$ A su vez, desde el punto de vista práctico, la experiencia condujo a valorar y ejercer la acción conjunta como medio de potenciar las capacidades individuales y posibilitar mejores resultados.

Sin embargo, recién en la reformulación de los principios cooperativos efectuada por la $\mathrm{ACl}$ en 1966 aparece explícitamente enunciado el principio conforme el siguiente texto: "Las cooperativas, para servir mejor a los intereses de sus miembros y comunidades, deben colaborar por todos los medios prácticos con otras cooperativas en los niveles local, nacional e internacional.»El informe de la Comisión que elaboró el proyecto de los nuevos principios asigna una especial importancia a este principio y destaca que el conjunto de ellos no ha sido reunido de manera a arbitraria o casual, sino que forman un sistema y son inseparables. Se apoyan y refuerzan unos con otros y deben ser observados íntegramente por todas las cooperativas, cualesquiera fueran sus objetivos y áreas de operación. ${ }^{13}$

De esta suerte la colaboración entre cooperativas vino a estar cabalmente reconocida dentro del contexto de los principios con igual jerarquía que los restantes entrando por la puerta ancha de la doctrina cooperativa y superando el status de un mero sobreentendido. Por su parte, la Declaración sobre la Identidad Cooperativa aprobada por el Congreso del Centenario de la ACl en1995 ratificó la inclusión de la cooperación entre cooperativas como principio. $Y$ en el documento de referencia se puntualiza que, aunque incorporado en la reformulación de 1966, «ha sido seguido, en grados distintos, desde los años 1850. ${ }^{14}$ De esa manera se reconoce el eslabonamiento de doctrina y

12 Martínez Charterina, Alejandro, sostiene que «este principio viene a terminar un proceso de solidaridad que junto a la solidaridad interna, que se realiza dentro de la cooperativa en cuyo seno se lleva a cabo un proceso de autoayuda por el que los socios tratan de satisfacer sus comunes necesidades de forma conjunta, considera la solidaridad externa, es decir la cooperación entre cooperativas o prolongación de la solidaridad interna para acabar un proceso de cooperación que, en última instancia, se refiere al mismo mundo en que vivimos y a la manera en que nos relacionamos unos con otros.» ( «Sobre el principio de cooperación entre cooperativas en la actualidad», Boletín de la Asociación Internacional de Derecho Cooperativo, N. 46 , Bilbao, 2012, p. 140).

13 ICA, Twenty-Third Congress Agenda and Reports, International Cooperative Alliance, 1966 , p. 85.

14 Mac Pherson, Ian, Cooperative Principles for the 21st Century, International Cooperative Alliance, Geneva, 1995, p. 29; Cano Ortega, Cristina, "Una perspectiva actual del sexto principio cooperativo: cooperación entre cooperativas», CIRIEC-España Revista Jurídica de Economía Social y Cooperativa, N. 27, Valencia, 2015, p. 288. 
práctica desde los mismos orígenes de las cooperativas, destacándose su particular relevancia. ${ }^{15}$

\section{La economía}

Resulta ocioso abundar en consideraciones acerca del fenómeno de la concentración empresaria en el mundo contemporáneo; solamente cabe decir que la tendencia es constantemente creciente y que hace mucho tiempo quedó superada la discusión acerca de la dimensión óptima de la empresa. Ahora solo cabe afirmar el slogan: "cuanto más grande mejor», facilitado por las permanentes adecuaciones legales que posibilitan instrumentar el crecimiento empresarial hasta magnitudes insospechadas. La globalización no ha hecho sino exacerbar esta propensión al crecimiento ilimitado que parecería haber superado los clásicos estudios acerca de la dimensión óptima de la empresa.

La cooperativa es también una empresa. Por lo tanto, la actuación en el mercado junto a las empresas de capital en un ámbito de competencia impulsa a que deban acomodarse a las exigencias del crecimiento como medio para sobrevivir y competir en ese ambiente. ${ }^{16}$ Las cooperativas habitan - forzosamente- en un medio no cooperativo y las reglas de éste suelen imponerles comportamientos que a menudo no desearían asumir, pero no les queda otra opción ya que de otra manera abandonarían el campo a las empresas de capital dejando así desprotegidos a sus asociados. Ello no implica, obviamente, que deban adoptar los mismos métodos que las otras empresas. ${ }^{17}$

Como se ha visto, la cooperación entre cooperativas en el terreno económico comenzó tempranamente y fue manteniéndose y expandiéndose en forma sostenida, pero cobró impulso a medida que el

15 Sin embargo, Münkner, Hans-H., Cooperative Principles and Cooperative Law, Friedrich Ebert Stiftung, Bonn, 1974, p,14, considera a la cooperación entre cooperativas como una práctica del principio de asistencia mutua por medio de la asociación derivado de la idea de autoayuda basada en la solidaridad; es decir, sin la jerarquía de un verdadero principio.

16 Con razón apunta Cristina Cano Ortega, «Una perspectiva actual del sexto principio cooperativo: cooperación entre cooperativas», CIRIEC-España Revista Jurídica de Economía Socia y Cooperativa, N. ${ }^{\circ} 27$, Valencia, 2015, p. 288: "Con el objetivo de que las cooperativas puedan desempeñar un papel importante en la actividad económica se les debe dotar de un régimen jurídico que les permita actuar en el mercado con las mismas posibilidades que las demás empresas con las que compiten.»

17 Resultan orientadoras las reflexiones de Javier Divar acerca del significado de los principios cooperativos, incluso más allá de las propias cooperativas: Las cooperativas: una alternativa económica, Dykinson, Madrid, 2011, p. 139. 
mundo económico iba agudizando la competencia y la integración. Por ello no extraña que la actualización de los principios cooperativos realizada por el Congreso de la ACI de 1966 haya incluido expresamente la colaboración entre cooperativas como sexto principio.

Algunos párrafos del informe presentado por la Comisión que se ocupó del tema en el mencionado Congreso son reveladores de la nueva situación que se había producido: «... la cooperación de segundo grado está jugando en el movimiento cooperativo actual. y jugará en el futuro, un papel mucho más importante que el que ha desempeñado hasta hoy. ... La idea de una mayor unidad dentro del movimiento cooperativo bajo varias designaciones - coordinación, concentración, integración- está ganando terreno entre los cooperadores porque en su mayoría se dan cuenta de que sus más serios competidores en la actualidad son las grandes organizaciones capitalistas, integradas horizontal y verticalmente. No hay por qué suponer que esta competencia vaya a disminuir en intensidad; por el contrario, podemos esperar que utilizando los modernos instrumentos técnicos, la empresa capitalista tenderá a continuar su evolución hacia monopolios y oligopolios... "Y remata con frase de contundente premonición: "La competencia que subsista no será la competencia de los grandes contra los pequeños sino la de los grandes entre sí. El movimiento cooperativo se encuentra potencialmente entre los más grandes. Solo necesita concentrar su poder en unidades de mayor magnitud aplicando consistentemente, sin restricciones, desde el plano local hasta el internacional, el principio de la cooperación entre cooperativas para exteriorizar su grandeza y actuar con éxito contra los monopolios. ${ }^{18}$

Estas consideraciones vertidas en la década de 1960 muestran claramente el panorama que se avecinaba y que el posterior desarrollo de la economía mundial no hizo sino ratificar, como acertadamente lo señaló A. Laidlaw en su informe al Congreso de la $\mathrm{ACl}$ realizado en Moscú en 1980. Mirando la perspectiva del año 2000 -que aparecía entonces remota y teñida de incógnitas - sostenía que el «sector cooperativo» como manifestación de la colaboración y el mutuo apoyo constituía el sentido del principio de la cooperación entre cooperativas y puntualizaba que no es una esperanza lejana sino un imperativo que el sentido común obligará a realizar de todas maneras. ${ }^{19}$

18 International Cooperative Alliance, Twenty Third Congress Agenda and Reports, London, 1966, p. 86.

19 Laidlaw, Alexander F., Las cooperativas en al año 2000, Intercoop, Buenos Aires, 1981, p. 90. 
La concreción de esa cooperación se materializa a través de distintos métodos, muchos de ellos ya acabadamente explorados por las sociedades de capital para realizar sus propios fines. Las circunstancias locales y de sectores de actividad van señalando cuáles resultan más convenientes y accesibles: integración horizontal y vertical; relaciones de coordinación o de subordinación; fusión en unidades económicas mayores o acciones en común permanentes o circunstanciales; etc. Lo que resulta imperioso es lograr el mayor beneficio para los asociados sin lesionar su participación democrática en la gestión.

\section{Condicionamiento legal}

Si bien es la fuerza intrínseca de la economía bajo el impulso de la técnica la que suele marcar el derrotero de los procesos de integración, no cabe duda acerca de que los regímenes legales y las regulaciones de las diferentes actividades en general constituyen el cauce por donde aquéllos deben transitar; a veces los facilitan y otras los obstaculizan. ${ }^{20}$

Las cooperativas suelen tropezar con dificultades legales que otras formas de organización empresaria no encuentran. Vale decir que la integración económica de las empresas de capital tiene un tratamiento legal amplio y permisivo, a tono con su naturaleza expansiva, en tanto que las cooperativas muchas veces tropiezan con restricciones propias de su consideración como empresas destinadas a unidades económicas de menor magnitud que no pueden abordar formas de integración que no se hallen expresamente contempladas en la legislación cooperativa. Ello les veda un extenso terreno abierto a las

20 Refiriéndose al principio de cooperación entre cooperativas Antonio Fici destaca el papel del derecho cooperativo afirmando que «la $\mathrm{ACl}$ no ha definido los contenidos de esta obligación, que carece así, por lo tanto, de la capacidad para imponer a las cooperativas una conducta cooperativa, a menos que el legislador sea más preciso a la hora de trasladar este principio al Derecho. Este es otro ejemplo del papel fundamental del Derecho, primero a la hora de conformar y, posteriormente, de garantizar el respeto de la identidad cooperativa.» ("La cooperación entre cooperativas en el derecho italiano y comparado», Boletín de la Asociación Internacional de Derecho Cooperativo, N. ${ }^{\circ} 48$, Bilbao, 2014, p. 117). Por su parte, los principios del derecho cooperativo europeo desarrollados por SGECOL (Grupo de Estudio sobre el Derecho Cooperativo Europeo) contienen una amplia referencia a la recepción jurídica del principio de cooperación entre cooperativas (Gemma Fajardo, Antonio Fici, Hagen Henrÿ, David Hiez, Hans-H. Münkner, lan Snaith, "Los principios del Derecho Cooperativo Europeo según SGECOL», ClRIEC-España Revista Jurídica de Economía Social y Cooperativa, N. ${ }^{\circ}$ 30, Valencia, 2017, p. 348 y ss). 
empresas de capital, al igual que la prohibición de realizar determinadas actividades - como el seguro y la banca, actividades que incentivan la integración - que se reservan en forma exclusiva a dichas empresas. Por lo tanto, las cooperativas se ven forzadas a recurrir a la formación de sociedades de capital — generalmente sociedades anónimas - para poder acceder a ciertas formas de mayor integración y a realizar actividades que demandan una fuerte concentración de recursos. De allí que la cooperación entre cooperativas asuma con frecuencia modalidades de organización propias de sociedades cuyos objetivos se encuentran en las antípodas.

Por otro lado, las formas de integración no societarias sino contractuales suelen considerarse no aplicables a las cooperativas por encontrarse legisladas separadamente de la legislación sobre cooperativas, con lo que se les retacea un amplio campo de actuación.

En suma, la cooperación entre cooperativas no se reduce, como prima facie podría suponerse, a la conformación de otras cooperativas o de cooperativas de grado superior (federaciones, uniones, centrales, etc.) sino que abarca un universo de posibilidades mucho más extenso, comprensivo tanto de las formas previstas en la legislación cooperativa como en la legislación societaria en general y en el régimen de los contratos. ${ }^{21}$ Ello no debería conducir, como a veces sucede, a considerar que las cooperativas por la mera circunstancia de su crecimiento violan las reglas que protegen la competencia, entre otras razones por cuanto las cooperativas se hallan abiertas al ingreso de todos los que desean hacerlo y porque no reparten ganancias derivadas de sus actividades sino que las devuelven a quienes las han producido o las reinvierten en reservas. En todo caso, el crecimiento de la integración cooperativa contribuye eficazmente a la defensa de la competencia, más que la propia acción de los organismos burocráticos creados para ejercer dicha defensa.

21 Cabe recordar que la Recomendación N. 193 de la OIT sobre la promoción de las cooperativas, además de incorporar los principios cooperativos tal como los establece la Declaración sobre la Identidad Cooperativa de la $\mathrm{ACl}$, se refiere en forma especial y amplia a la cooperación entre cooperativas en el punto 13 que reza: «Con miras a la promoción del movimiento cooperativo, los gobiernos deberían fomentar condiciones que favorezcan el desarrollo de vínculos técnicos, comerciales y financieros entre todas las formas de cooperativas, con el objeto de facilitar el intercambio de experiencias y la participación en los riesgos y beneficios.» Por parte, Hagen Henrÿ, «Public International Cooperative Law» en Cracogna, D., Fici, A., Henrÿ, H, (Editors), International Handbook of Cooperative Law, Springer, Heidelberg, 2013, p. 66, afirma que dicha Recomendación constituye el núcleo del Derecho Público Internacional Cooperativo y sería, por tanto, de obligado cumplimiento para los gobiernos. 


\section{Conclusión}

Con frecuencia, particularmente en América Latina, se utiliza la expresión «integración cooperativa» para hacer referencia al principio de cooperación entre cooperativas. Y si acudimos al diccionario de la Real Academia de la Lengua encontramos que la expresión resulta acertada en tanto significa «unir las partes que forman un todo». Allí radica el sentido cabal de la cooperación entre cooperativas: en el reconocimiento de que ellas - cualquiera sea su actividad específica, su ubicación geográfica, su dimensión económica, etc.- forman parte de un movimiento que alienta idénticos valores y profesa los mismos principios.

Los teóricos del cooperativismo desarrollaron distintas concepciones acerca de los alcances de la unidad y el destino del movimiento cooperativo; es decir, sobre cuál es el «todo» que sus partes conforman. Así, entre otros, se destacan por su ambiciosa concepción Charles Gide y Ernst Poisson, quienes postularon el «reino del consumidor» y la «república cooperativa», respectivamente. A su vez, con alcances más modestos y más realistas, Georges Fauquet desplegó la tesis del «sector cooperativo»22, todos ellos fundados en la unidad esencial —aun no cabalmente percibida por los propios cooperativistas- de un movimiento que se identifica por valores y principios comunes.

Esa unidad se expresa tanto en la acción económica conjunta a través de sus variadas manifestaciones como en la acción representativa, de difusión y de educación. Ambas son igualmente importantes y necesarias puesto que la acción económica también depende del conocimiento y aceptación que la sociedad tenga de las cooperativas y de que la opinión pública y los poderes gubernamentales reconozcan su naturaleza y beneficios. ${ }^{23}$ Las dos dimensiones de la integración -económica y representativa - confluyen en la unidad y expansión del movimiento cooperativo ${ }^{24}$ sintetizando la necesidad y el principio.

22 Si bien estas elucubraciones doctrinarias parecerían haber perdido actualidad ellas constituyen un elemento que subyace en el pensamiento cooperativo y que la práctica alimenta de manera permanente, aunque inconsciente.

${ }^{23}$ Cracogna, Dante, "Naturaleza cooperativa y políticas públicas», en AAVV, Políticas Públicas y Cooperativas, Intercoop, Buenos Aires, 2020, p. 97/98.

24 Refiriéndose a la integración económica y la integración representativa afirma Fici, Antonio, "La cooperación entre cooperativas en el derecho italiano y comparado», Boletín de la Asociación Internacional de Derecho Cooperativo, N. 48, Bilbao, 2014, p. 116, que «estas dos formas de integración no pueden ser desvinculadas completamente, dado que la integración económica podría tener también una repercusión política e ideológica en todo el sector cooperativo, mientras que, por otra parte, una posible forma de promover el movimiento cooperativo puede ser a través de una actividad económica, por ejemplo, de tipo financiera.» 


\section{Referencias}

ABBAGNANO, Nicola. 1993. Diccionario de Filosofía, trad. A. Galletti, Fondo de Cultura Económica, México.

ARISTÓTELES. 2000. METAFÍSICA, trad. T. Calvo Martínez, Gredos.

BAILEY, Jack. 1960. The British Co-operative Movement, Hutchinson University Library, London.

CANO ORTEGA, Cristina. 2015. "Una perspectiva actual del sexto principio cooperativo: cooperación entre cooperativas», CIRIEC-España Revista Jurídica de Economía Social y Cooperativa, N. ${ }^{\circ} 27$, Valencia.

COLE, G.D.H. 1944. A Century of Co-operation, George Allen \& Unwin Ltd.

CRACOGNA, Dante. 2019. «El principio de autonomía e independencia en la declaración sobre la identidad cooperativa». Boletín de la Asociación Internacional de Derecho Cooperativo, n. 55 (diciembre), 19-34. https://doi. org/10.18543/baidc-55-2019pp19-34.

CRACOGNA, Dante. 2020. «Naturaleza cooperativa y políticas públicas», en AAVV, Políticas Públicas y Cooperativas, Intercoop, Buenos Aires.

DIVAR, Javier. 2011. Las cooperativas: una alternativa económica, Dykinson, Madrid.

$\mathrm{FICl}$, Antonio. 2014. "La cooperación entre cooperativas en el derecho italiano y comparado», Boletín de la Asociación Internacional de Derecho Cooperativo, N. ${ }^{\circ} 48$, Bilbao.

HENRŸ, Hagen. 2013. «Public International Cooperative Law» en Cracogna, D., Fici, A., Henrÿ, H, (Editors), International Handbook of Cooperative Law, Springer, Heidelberg.

HOLYOAKE, Georges Jacob. 1975. Historia de los Pioneros de Rochdale, trad. B. Delom, Intercoop, Buenos Aires.

International Cooperative Alliance. 1966. Twenty-Third Congress Agenda and Reports, London.

FAJARDO, Gemma, Antonio Fici, HAGEN Henrÿ, David HIEZ, Hans-H. MÜNKNER, Ian SNAITH. 2017. "Los principios del Derecho Cooperativo Europeo según SGECOL», CIRIEC-España Revista Jurídica de Economía Social y Cooperativa, N. ${ }^{\circ} 30$, Valencia.

LAIDLAW, Alexander F. 1981. Las cooperativas en al año 2000, Intercoop, Buenos Aires.

LAMBERT, Paul. 1959. La Doctrine Coopérative, Les Propagateurs de la Coopération - La Fédération Nationale des Coopératives de Consummation, Bruxelles - Paris.

MARTÍNEZ CHARTERINA, Alejandro. 1990. Análisis de la integración cooperativa, Universidad de Deusto, Bilbao.

MARTÍNEZ CHARTERINA, Alejandro. 2012. «Sobre el principio de cooperación entre cooperativas en la actualidad», Boletín de la Asociación Internacional de Derecho Cooperativo, N. ${ }^{\circ} 46$, Bilbao.

MAC PHERSON, Ian. 1995. Cooperative Principles for the 21st Century, International Cooperative Alliance, Geneva. 
MÜNKNER, Hans-H. 1974. Cooperative Principles and Cooperative Law, Friedrich Ebert Stiftung, Bonn.

THOMPSON, David J. 1994. Weavers of Dreams. Founders of the Modern Cooperative Movement, Center for Cooperatives, University of California, Davis.

WATKINS, William Pascoe. 1970. The International Cooperative Alliance 18951970, International Cooperative Alliance, London. 


\section{Derechos de autor}

El Boletín de la Asociación Internacional de Derecho Cooperativo es una revista de acceso abierto lo que significa que es de libre acceso en su integridad inmediatamente después de la publicación de cada número. Se permite su lectura, la búsqueda, descarga, distribución y reutilización legal en cualquier tipo de soporte sólo para fines no comerciales y según lo previsto por la ley; sin la previa autorización de la Editorial (Universidad de Deusto) o el autor, siempre que la obra original sea debidamente citada (número, año, páginas y DOI si procede) y cualquier cambio en el original esté claramente indicado.

\section{Copyright}

The International Association of Cooperative Law Journal is an Open Access journal which means that it is free for full and immediate access, reading, search, download, distribution, and lawful reuse in any medium only for non-commercial purposes, without prior permission from the Publisher or the author; provided the original work is properly cited and any changes to the original are clearly indicated. 